\title{
COMMENTARY
}

\section{ACCESS TO ABORTION FOR UNDOCUMENTED PERSONS DURING THE COVID-19 PANDEMIC}

\author{
FRÉDÉRIQUE CHABOT*
}

Action Canada for Sexual Health and Rights ('Action Canada') is a national organisation committed to advancing and upholding sexual and reproductive health and rights in Canada and globally. Building on the 50-year legacy of the organisations that formed Action Canada, we work to promote health, equity, wellbeing and rights related to sexuality and reproductive health to advance progressive policies on access to abortion, stigma-free healthcare, gender equality, LGBTQ+ rights and inclusive sex-ed, among other issues that intersect with bodily autonomy, gender, sexuality and reproduction.

In March 2020, as the world quickly pivoted towards a pandemic response, Action Canada connected with partners across the country to monitor shifting needs and how providers of sexual and reproductive health services were adapting to this novel situation in Canada. We saw some concerning gaps in services leading to a disproportionate impact on stateless and undocumented persons. ${ }^{1}$

Action Canada's activities include the operation of a 24-hour toll-free pregnancy information and referral service - the Access Line - paired with a national abortion fund to ensure those who face barriers can access abortion care. Calls to the Access Line more than doubled in the first months of 2020. Callers were looking for ways to access safe abortions during the pandemic. Conference calls with our network of sexual health centres across the country, surveys to partners and a variety of national organisations revealed concerning trends in relation to stateless persons and those with precarious immigration status and their ability to access sexual and reproductive health care.

Action Canada, working with the National Abortion Federation ('NAF Canada'), observed that access to abortion in some regions decreased, even though health officials from every province and territory declared abortion an essential service. While many hospital-based programs continued at their usual volume and clinics did their best to maintain services at the same level, many successfully, some decisions made by hospitals about who could access their services, paired with increased travel challenges, resulted in restricted access. Providers and

Frédérique Chabot (she/her) is the Director of the Health Promotion Team at Action Canada, managing, among other programs and activities, the Access Line, a hotline where the Canadian public can access sexual and reproductive health information, support and referrals for services. Before joining Action Canada, Chabot worked in the community health sector as the Women HIV/AIDS prevention coordinator at the AIDS Committee of Ottawa. She was also a board member of POWER, a sex worker right organization, from 2008 to 2018.

1 Because Action Canada's national abortion fund aims to be as low-barrier as possible, we do not ask for a person's immigration or citizenship status or gather much demographic data that would make it possible to segregate stateless people from people who have precarious immigration status. We work with whoever is uninsured and face specifically related health care barriers. 
activists were concerned about access to abortion beyond the first trimester as it often requires further travel for anyone residing outside of urban centres where abortion care is available. For example, bus routes were cancelled, flights cancelled and provinces closed their borders. Further, traditionally Action Canada assists persons in finding care outside of Canada, most notably in the United States, where care is not available in Canada. While not everyone is impacted to the same degree, depending on their social, financial and geographic positioning, these barriers were experienced disproportionately by those with precarious immigration status. For stateless and migrant persons with precarious status, accessing alternative care across the border was not a viable option.

A significant percentage of those supported more fulsomely by Action Canada are individuals requiring abortion care beyond what is available in Canada. This currently requires travel to the United States, although it is an insured service in Canada. This means we really get to know the needs and barriers faced by people who need those services. Prior to the pandemic, Action Canada and NAF Canada used its funds to support access in Canada by paying procedure fees and creating partnerships with a network of health care providers who were willing and able to see undocumented patients who needed abortions. Since the pandemic, of those who ended up unable to access abortion at all, the majority were undocumented individuals. While most Canadian citizens who saw doors close in front of them had the option of travelling to the United States, despite the difficulty of such a journey, undocumented and uninsured individuals faced the harshest challenges in accessing health care during this pandemic. For those who could access care, their ability to pay their procedure fees depended on the joint capacity of two non-profit organisations with donation-based funds. The fact that so many individuals in Canada depend on charities to access abortion care, which is deemed essential under the Canada Health Act, underlines the inadequacy of existing government programs and a failure to comply with international human rights law. ${ }^{2}$

Across populations, the main barrier to abortion care is financial as people have to pay for travel and accommodations to access a point of service or because they have to pay procedure fees out of pocket. With this in mind, it is important to note that, while many people in Canada lost their income during the pandemic, the majority, including some non-citizens, would have been able to access Canada's recovery benefits such as the Canada Recovery Benefit, which could mitigate such a barrier. ${ }^{3}$ That said, people without a Social Insurance Number were denied financial aid at a time when businesses shut down, jobs disappeared and entire sectors of the economy slowed down, leaving many without any financial resources. ${ }^{4}$ Job sectors that disproportionately employ migrant workers and those with tenuous immigration status, including accommodation, caregiving, food service and retail, were among the hardest hit by the pandemic. ${ }^{5}$

One solution to the inability to or the delay in accessing abortion care is medication abortion. In July 2015, Health Canada approved the abortion pill Mifegymiso, the World Health Organization's gold standard for medication

2 Canada Health Act, RSC 1985 c C-6, s 9.

3 'Canada Recovery Benefit', Government of Canada (Web Page, 15 April 2021) $<$ https://www.canada.ca/en/revenue-agency/services/benefits/recovery-benefit/crb-whoapply.html>.

4 ibid.

5 'COVID-19 in Canada: A Six-month Update on Social and Economic Impacts', Statistics Canada (Web Page, 20 October 2020) <https://www150.statcan.gc.ca/n1/pub/11-631-x/11631-x2020003-eng.htm>. 
abortion. ${ }^{6}$ Making it available to people in Canada was an important step in addressing historical gaps in access to abortion outside of urban centres, as it can be offered by primary care providers like family doctors, nurse practitioners and midwives. In real terms, widely available medical abortion improves access by allowing individuals to access abortion care earlier in their pregnancy, reducing the number of pregnancies carried to a more advanced gestation, when seeking abortion care becomes more logistically and financially complicated (ie, having to travel further, having to cross borders, needing to take more time off work, child/eldercare, etc). However, for undocumented people, the potential of medical abortion is largely out of reach since access to this care depends on having a health card and/or the ability to pay for clinical fees out of pocket and/or travel. Further, if the closest place or only place to access this medication is in the United States, for example, this requires the crossing of an international border, which means having documentation is essential. The price tag for Mifegymiso hovers between CAN300 and CAN450 for a dose. ${ }^{7}$ When combined with additional clinical, diagnostic and doctors' fees, the price can be upwards of CAN1,000 per patient. ${ }^{8}$ Programs that cover health fees associated with abortion care for undocumented individuals are few and far in between. While COVID-19 benefitted the majority, through accelerated access to medication abortion care through low-touch or notouch telemedicine appointments, undocumented people were not equally benefitted.

We noted some other concerning trends regarding surgical abortion and abortion care later in pregnancy. In the early months of the pandemic, hospitals that usually saw patients from all over Canada because they offer later abortion care closed their doors to patients outside of their province or their health region because of COVID-19 restrictions. ${ }^{9}$ This meant that people had to access abortion care in the United States earlier on during their pregnancy as centres who offered later care were effectively not open to the public anymore. For example, people would typically travel to cities like London, Ontario or Vancouver, British Columbia, for abortion care later in pregnancy. Due to restrictions on interprovincial travel, people who required abortion later in pregnancy, who lived in Nova Scotia or Manitoba, for example, had to travel to Colorado or Washington.

Having to travel to the United States can be an unmanageable obstacle when a person is precariously housed, does not have a cell phone, has a criminal record, struggles with mental health issues or substance use issues, has a complex health history, is a victim of domestic violence or reproductive coercion, faces constant emergencies due to poverty, has intellectual or cognitive disabilities, has poor executive function or is underage. Even those able to travel to the United States during the pandemic had to contend with new requirements. These included a

6 World Health Organization, Safe Abortion: Technical and Policy Guidance for Health Systems (2nd ed, 2012), 3. See also 'FAQ: The Abortion Pill Mifegymiso', Action Canada for Sexual Health \& Rights (Web Page, 4 June 2019) $<$ https://www.actioncanadashr.org/resources/factsheets-guidelines/2019-04-06-faq-abortionpill-mifegymiso>.

7 Canadian Agency for Drugs and Technologies in Health, Pharmacoeconomic Review Report: Mifepristone and Misoprostol (Mifegymiso) (2017) Appendix 1 Table 5.

8 See, eg, 'Abortion', Centre De Santé Des Femmes De Montréal (Web Page) $<\mathrm{http}$ //www.csfmontreal.qc.ca/wp/en/services/abortion/>.

9 This proposition is predominately based on the author's own observations. See also 'Further Reductions in Non-urgent and Emergent Care at London Health Sciences Centre', London Health Sciences Centre (Web Page, 29 March 2020) <https:/www.lhsc.on.ca/furtherreductions-in-non-urgent-and-emergent-care-at-london-health-sciences-centre $>$. 
mandatory letter from their health care provider stating they are accessing essential health care so they could cross the border (and being at the mercy of border agents' goodwill), mandatory COVID-19 testing before boarding flights, the cancelling and rebooking of flights, lockdowns and quarantine requirements. ${ }^{10}$

For someone who does not have Canadian citizenship and/or a passport that enables travel to the United States, it is a dead end. Likewise, for those whose visas have expired due to extended stays in Canada during the pandemic, they are unable to cross into the United States for fear of deportation and/or being unable to reunite with their family when they return to Canada.

As a society, we do not often appreciate why abortion seekers need access to care in the second and third trimester. We know one of the main reasons that people need care later in pregnancy is because struggled to access care in the first place. This is one reason why undocumented people and those in precarious immigration situations are a group of people we often support accessing later abortion care. Many of them do not know where to go for an abortion as they are not connected to health care services, face waiting period before they can access health insurance because of immigration policies and provincial health coverage eligibility requirements, need time to collect money to pay for the abortion out of pocket or for travel to a point of service, are afraid of seeking health care because of their immigration status or statelessness, are fearful of deportation should they engage with the health system, experience linguistic barriers or experience restriction on their movement from employers or sponsors for numerous reasons. This means that many people who are already in extremely vulnerable situations find themselves more likely to face complex barriers in accessing an abortion.

This is without considering the difficulty in accessing culturally safe and relevant abortion services and protecting confidentiality. For undocumented individuals whose primary language is not English, language barriers and a lack of translation/interpretation resources within health care settings often result in complex situations where communication is hindered. This makes creating an appointment, coordinating financial support, establishing informed consent and communicating about the procedure and aftercare incredibly difficult and time intensive. When hospital or clinic-based interpretation services are not available, community-based interpreters are sought. ${ }^{11}$ However, in many cases, this can jeopardize the patient's anonymity or confidentiality as members of their potentially small communities may be engaged to provide interpretation services. Likewise, since the majority of providers require patients to have a support person on the day of their procedure, undocumented individuals may have less access to supportive networks or communities depending on their situation, and this may pose a significant barrier. Where possible, doula collectives meet this need, but are often only accessible in large urban centres.

10 'COVID-19 Information - Canada', US Embassy \& Consulates in Canada (Web Page, 13 July 2021) <https://ca.usembassy.gov/covid-19-information-canada-3/>; Loprespub, 'The COVID-19 Pandemic and Air Ticket Reimbursements', Hillnotes (Web Page, 15 April 2021) $<$ https://hillnotes.ca/2021/04/15/the-covid-19-pandemic-and-air-ticket-reimbursements/>;

'Fact Sheet: DHS Measures on the Border to Limit the Further Spread of Coronavirus', US

Department of Homeland Security (Web Page, 22 October 2021) $<$ https://www.dhs.gov/news/2020/10/19/fact-sheet-dhs-measures-border-limit-furtherspread-coronavirus $>$.

11 Anjum Sultana et al, Language Interpretation Services in Health Care Settings in the GTA (Wellesley Institute 2018) 5, 11. 
Health is a fundamental human right. 12 Governments, as duty bearers, are required to ensure that abortion care, as part of the right to health, is available, accessible, accepted and of quality. Despite this, governments routinely deny and violate the right to health, particularly for individuals without immigration status or documentation. This is particularly jarring in Canada, a high-income country with universal health care maintains vital segments of its economy through undocumented labour. ${ }^{13}$ There are no federal or provincial health care policies which legally provide undocumented migrants, including stateless individuals, with a right to access healthcare.

Being denied an abortion, unsurprisingly, has a serious impact on individuals. One study, which involved research conducted over 10 years on approximately 1,000 women who had or were denied abortions, tracked the impact on mental, physical and economic health. ${ }^{14}$ Although the primary focus of the study was on women's experiences, they also gathered information about the health and development of the children born from women who had sought abortions and were denied. This study found that those denied a wanted abortion are four times more likely to live in poverty than those who accessed care. In addition, women who are denied abortions are more likely to: experience serious complications during their pregnancy including eclampsia and death, stay tied to abusive partners, suffer anxiety and loss of self-esteem in the short term after being denied abortion, lack aspirational life plans for the coming year, have weaker maternal bonds with their children and raise children without supports from other adults, among other outcomes. ${ }^{15}$ This study does not speak to the further challenges faced by stateless people and migrant with precarious statuses.

When government and health system policies restrict or fail to ensure the accessibility of abortion, people can be compelled to resort to clandestine, unsafe abortions, particularly those who cannot afford to travel or seek private care. Restricted access to abortion does not stop abortions, it just makes abortion less safe. ${ }^{16}$ In Canada, when we consider that during the pandemic, the vast majority of people who were denied an abortion were undocumented or had precarious immigration status, we are led to assume that some of them sought to self-manage their abortions without the support of health care providers. ${ }^{17}$

One year later, Action Canada is resolute in its commitment to connecting the dots between sexual and reproductive rights and the struggles of migrant, undocumented and stateless people. In Canada, we cannot advocate for improved access to a comprehensive package of sexual health services, including abortion, without centring the challenges experienced by those most impacted by laws, policies and practices that erect barriers to health care. Action Canada and NAF Canada continue to work with health care providers and institutions to create

12 Universal Declaration of Human Rights, GA Res 217A (III), UN GAOR, UN Doc A/810 (10 December 1948) art 25.

13 Krista Hessey, "Everyone is at Risk": Migrants and Undocumented Workers Need the COVID-19 Vaccine Too', Global News (online, 21 June 2021) $<$ https://globalnews.ca/news/7706181/covid-19-vaccine-migrants-undocumented-workers/>.

14 Sarah Miller, Laura R Wherry and Diana Greene Foster, 'What Happens after an Abortion Denial? A Review of Results from the Turnaway Study' (2020) 110 AEA Papers and Proceedings.

15 ibid

16 'Preventing Unsafe Abortion' World Health Organization (Web Page, 25 September 2020), $<$ https://www.who.int/news-room/fact-sheets/detail/preventing-unsafe-abortion>.

17 This proposition is based on the author's own observations. 
programs offering later abortion care in Canada because it is central to realising undocumented people's right to abortion care. We advocate for firmly integrating pathways to services for the uninsured and undocumented into the heart of those programs.

We also join our voice to the many who fight fiercely for Status for All - a campaign calling for the permanent status and rights of migrants and undocumented people generally. ${ }^{18}$

Finally, we seek to highlight that, while COVID-19 has exposed and worsened existing inequalities, there are also more nefarious forces at work using the pandemic to roll back rights in purposeful ways. This has occurred in the United States, Texas and Indiana moved to ban most abortions during the pandemic by classifying them as 'non-essential', 19 and in Poland, where a bill to ban virtually all abortions has been revived. ${ }^{20}$ These are examples of the 'shock doctrine', which is the exploitation of national crises to establish controversial and questionable policies, while citizens are too emotionally and physically distracted to engage, develop an adequate response and resist effectively. ${ }^{21}$

To advance sexual, reproductive and gender justice, it is crucial to connect and organise with a diversity of people and movements that seek social justice for all, including justice for migrants, undocumented and stateless people.

18 'Together for Full \& Permanent Immigration Status for All', Migrant Rights Network (Web Page, 2021) $<$ https://migrantrights.ca/status-for-all/>.

19 See Tony Cook and Chris Sikick, 'What a Coronavirus Executive Order Means for Abortions in Indiana', Indianapolis Star (online, 31 March 2020) $<$ https://www.indystar.com/story/news/politics/2020/03/31/coronavirus-indiana-whatexecutive-order-means-abortions/5096617002/>; David Crary and Iris Samuels, 'Some GOPLed States Target Abortion Done Through Medication', Associated Press News (online, 12 April 2021) <https://apnews.com/article/medication-postal-service-legislation-abortioncoronavirus-pandemic-ecd8841541bcb46ec6a15bda3e1c3682>; Jennifer Haberkorn, 'Amid Coronavirus Outbreak Some Red States Move to Restrict Abortion, Spurring Legal Fight', Los Angeles Times (online, 2 April 2020) < https://www.latimes.com/politics/story/2020-0402/red-states-block-abortion-coronavirus-outbreak>; Abigail Tracy, "The Pandemic Is Being Used as Cover": Planned Parenthood's Alexis McGill Johnson on the Dangerous New War on Abortion', Vanity Fair (online, 3 April 2020) $<$ https://www.vanityfair.com/news/2020/04/coronavirus-planned-parenthood-alexis-mcgilljohnson-abortion-bans>.

20 See Brian Grodsky, 'Poland's Anti-Abortion Push Highlights Pandemic Risks to Democracy', The Conversation (online, 26 November 2020) <https://theconversation.com/polands-antiabortion-push-highlights-pandemic-risks-to-democracy-150520>; Shaun Walker, 'Concerns Over Polish Government Tightening Abortion Laws During COVID-19 Crisis', The Guardian (online, 15 April 2020 ) $<$ https:/www.theguardian.com/world/2020/apr/14/concerns-over-polish-governmenttightening-abortion-laws-during-covid-19-crisis>; 'Poland Enforces Controversial NearTotal Abortion Ban', $B B C$ (online, 28 January 2021) <https://www.bbc.com/news/worldeurope-55838210>.

21 See, eg, Naomi Klein, The Shock Doctrine (Knopf Canada 2007). 